Eur J Clin Chem Clin Biochem

1995; 33:267-269

(c) 1995 Walter de Gruyter \& Co. Berlin. New York

\title{
Platelet Count and Platelet Indices at Various Stages of Normal Pregnancy in Smoking and Non-Smoking Women
}

By Patricia E. A. M. Mercelina-Roumans ${ }^{1}$, Johannes M. H. Ubachs ${ }^{1}$ and Jan W. J. van Wersch ${ }^{2}$

1 Department of Obstetrics and Gynaecology

2 Department of Haematology

De Wever Hospital, Heerlen, The Netherlands

(Received November 11, 1994/February 2, 1995)

Summary: Our objective was to compare the platelet count and platelet indices of smoking and non-smoking women at different stages of normal pregnancy.

Study design: In 247 non-smoking and 123 smoking healthy pregnant women the platelet count, the mean platelet volume, the platelet distribution width and the plateletcrit were compared at $0-10,11-20,21-30$ and $31-40$ weeks of pregnancy. Exclusion criteria were a diastolic pressure $\geq 90 \mathrm{mmHg}$, an endocrine disease, a coagulation disorder, acetylsalicylic acid or phenprocoumon use. A women was considered a smoker if she smoked more than 4 cigarettes a day. Non-smokers were defined as women reporting no smoking at all. Blood samples were run on the Sysmex NE-8000.

Results: There was no significant difference between the platelet count in the two groups. In the non-smoking group, the platelet count showed a significant decrease with gestational age $\left(287 \times 10^{9} / 1\right.$ to $\left.258 \times 10^{9} / 1\right)$. This was not the case in the smokers group. The mean platelet volume of the smokers was significantly lower than that of the non-smokers in the last ten weeks of pregnancy $(10.4 \mathrm{fl}$ versus $10.7 \mathrm{fl})$. The platelet distribution width and the plateletcrit did not change under the influence of cigarette smoking.

Conclusion: Smoking during pregnancy does not significantly affect platelet count or platelet indices.

\section{Introduction}

In recent years there has been a broad interest in defining the mechanisms responsible for the adverse effects of cigarette smoking $(1-3)$. Various reports have focused on the influence of smoking on platelets because of a possible association between smoking, an alteration of blood platelets and atherosclerosis (4-7). Some of these studies showed an increase of platelet turnover and a decrease of platelet survival in smokers $(4,7)$. The increased destruction of platelets, however, was not sufficient to reduce the number of circulating platelets. Platelet counts either remained normal $(4,8)$ or were increased $(9,10)$. Smoking and platelet behaviour during pregnancy were not addressed up to now. Most platelet studies have been confined to platelet counts in nor- mal pregnancy regardless of the smoking behaviour of the women, although the combination of platelet and platelet size indices as mean platelet volume (MPV), platelet distribution width (PDW) and plateletcrit (PCT) might provide better insight into platelet biology during pregnancy. The aim of this study was to assess the platelet count and platelet indices (MPV, PDW and PCT) at various stages of normal pregnancy in smoking and nonsmoking women.

\section{Materials and Methods}

Two hundred and forty seven non-smoking and 123 smoking healthy pregnant women attending the department of obstetrics for monitoring of their pregnancy were included in the study. The platelet count and platelet indices were determined at four differcnt 
stages $(0-10,11-20,21-30,31-40$ weeks) of pregnancy. Not all patients were checked in all four stages.

Exclusion criteria were a diastolic pressure $\geq 90 \mathrm{mmHg}$, an endocrine disease or a coagulation disorder. None of the patients used acetylsalicylic acid or phenprocoumon. The known duration of the gestation was based on the last menstrual period and an ultrasound determination between 8 and 14 weeks. The number of cigarettes smoked per day was estimated by the patient, in most cases confirmed by her partner. A women was considered a smoker if she smoked more than 4 cigarettes a day. The group of women who smoked more than 15 cigarettes a day was too small to subdivide the smokers into an intermediate smoking level group (5-15 cigarettes per day) and a group of heavy smokers ( $>15$ cigarettes per day). Non-smokers were defined as women reporting no smoking at all. The basic characteristics of these patients are given in table 1 .

Blood samples were drawn between 8.30 and 9.30 a.m. into EDTA-K $\mathrm{K}_{2}$ containing tubes (Sarstedt, Germany) and kept at room temperature for at most 5 hours before they were run on the Sysmex NE-8000 (TOA Medical Electronics Corp., Kobe, Japan) Correlations were determined by linear regression analysis with the method of the least squares. The significance of the differences of the median values of the various groups was assessed by the MannWhitney-Ifilcoxon test.

\section{Results}

In table 2 the comparison of the platelet counts of the smoking and non-smoking females at four stages of pregnancy is given. In the non-smoking group, the platelet count showed a slight but significant decrease with gestational age. The group started with a median platelet count of $287 \times 10^{9} / 1$ and ended with a platelet count of $258 \times 10^{9} / 1(\mathrm{p}=0.002)$. The decrease from $283 \times 10^{9} / 1$ to $264 \times 10^{9} / 1$ in the smokers group however was not significant $(p=0.86)$.

The MPV of the smokers was significantly lower than the volume of the non-smokers in the last ten weeks of pregnancy (10.4 versus $10.7 ; p=0.02$ ). The MPV in the non-smoking group did not change during gestation. This quantity was also more or less stable in the smoking group. The PDW of the two groups is compared and did not change under the influence of smoking. There was also no difference in the plateletcrit values. In the nonsmoking group the PDW increased significantly from the beginning to the end of pregnancy $(11.7 \%$ to $12.3 \%$; $p=0.03$ ). This was not the case in the smoking group. The PCT in the non-smokers decreased significantly throughout pregnancy (26.3 $1 / 1$ to $24.9 \mathrm{l} / \mathrm{l} ; \mathrm{p}=0.04)$. The PCT in the smokers also decreased throughout pregnancy, but this difference was not significant.

\section{Discussion}

In the present study the only difference in platelet counts observed was a slight but significant decrease with gestational age in the non-smoking group. Platelet survival is known to diminish in late pregnancy (11). This is due to an accelerated state of coagulation and fibrinolysis which increases towards term (12). Haemodilution in pregnancy may be another explanation for the decrease

Tab. 1 Basic characteristics of the pregnant women.

\begin{tabular}{|c|c|c|c|}
\hline Groups of patients & $\begin{array}{l}\text { Age } \\
\text { (a) } \\
\text { median } \\
\text { (interquartile range) }\end{array}$ & Parity & $\begin{array}{l}\text { Cigarettes } \\
\text { per day } \\
\text { median } \\
\text { (interquartile range) }\end{array}$ \\
\hline Non-smokers, normal pregnancy $(n=247)$ & $\begin{array}{l}30 \\
(27-33)\end{array}$ & $\begin{array}{l}47.9 \% \text { primi } \\
52.1 \% \text { multi }\end{array}$ & 0 \\
\hline Smokers, normal pregnancy $(n=123)$ & $\begin{array}{l}29 \\
(25-32)\end{array}$ & $\begin{array}{l}\text { 47.8\% primi } \\
52.2 \% \text { multi }\end{array}$ & $\begin{array}{l}10 \\
(5-15)\end{array}$ \\
\hline
\end{tabular}

Tab. 2 Comparison of the platelet counts of the smoking (S) and non-smoking (NS) females at four stages during normal pregnancy.

\begin{tabular}{|c|c|c|c|c|c|c|c|c|}
\hline \multirow{5}{*}{$\begin{array}{l}\text { Gestational age (weeks) } \\
\text { Patient groups } \\
\text { Sample size } \\
\text { Median }\left(10^{9} / 1\right)\end{array}$} & \multicolumn{8}{|c|}{ Platelets } \\
\hline & \multicolumn{2}{|l|}{$0-10$} & \multicolumn{2}{|c|}{$11-20$} & \multicolumn{2}{|c|}{$21-30$} & \multicolumn{2}{|c|}{$31-40$} \\
\hline & NS & $\mathrm{S}$ & NS & $S$ & NS & $\mathbf{S}$ & NS & $\mathrm{S}$ \\
\hline & 93 & 46 & 66 & 29 & 119 & 45 & 180 & 68 \\
\hline & $\left.287^{1}\right)$ & $\left.283^{\prime}\right)$ & $\left.264^{2}\right)$ & $\left.267^{2}\right)$ & $264^{3}$ ) & $\left.283^{3}\right)$ & $\left.258^{4}\right)$ & $\left.264^{4}\right)$ \\
\hline Lower quartile $\left(10^{9} / 1\right)$ & 232 & 215 & 230 & 239 & 226 & 247 & .211 & 232 \\
\hline Upper quartile $\left(10^{9} / 1\right)$ & 325 & 322 & 302 & 299 & 308 & 334 & 302 & 312 \\
\hline $\mathrm{p}$-value of MWW-test & \multicolumn{2}{|c|}{$\left.{ }^{1}\right)$ vs. ${ }^{1}$ ): n.s. } & \multicolumn{2}{|c|}{${ }^{2}$ ) vs. ${ }^{2}$ ): n.s. } & \multicolumn{2}{|c|}{$\left.{ }^{3}\right)$ vs. ${ }^{3}$ ): n.s. } & \multicolumn{2}{|c|}{$\left.{ }^{4}\right)$ vis. ${ }^{4}$ ): n.s. } \\
\hline
\end{tabular}

MWW = Mann-Whitney-Wilcoxon-test 
of platelets (13). It is remarkable that this decrease of platelets does not occur in the smoking group.

Most platelet studies in normal pregnancy have been confined to platelet counts, but the platelet count alone is not conclusive. Platelet size indices provide more information about platelet biology. The MPV is an indication of the amount of young platelets. Fay et al. (14) studied platelet count and indices in blood samples from 2066 healthy women with an uncomplicated pregnancy. The MPV remained stable until 35 weeks gestation and rose dramatically thereafter. Ahmed et al. (15) studied the MPV in healthy pregnants. This quantity remained constant between the first trimester and the end of normal pregnancy. In patients who became pre-eclamptic, a persistent increase in MPV was found. Hutt et al. (16) found that the MPV increased 2-3 weeks before the development of pre-eclampsia.

In our study the MPV was significantly lower in the last ten weeks of pregnancy in the smoking than in the nonsmoking group. The MPV of the non-smokers remained almost constant from the beginning to the end of pregnancy.

Less has been published regarding PDW and PCT in pregnancy. In the present study these indices remained more or less constant in both smoking and non-smoking women throughout pregnancy. This is an accordance with earlier results of our group (17), in which platelet indices were studied in normal pregnancy.

In several studies the effect of the smoking constituents nicotine and carbon monoxide on platelet aggregation in non-pregnants has been evaluated in vivo and in vitro $(18-21)$. They generally showed evidence of platelet activation. Smokers had an enhanced aggregation of platelets, although the platelet count did not differ from non-smokers. The present study indicates that smoking during pregnancy does not affect platelet count and platelet indices in a clinically relevant way.

However, the effect of the combination of smoking and pregnancy on platelet aggregation still has to be assessed.

\title{
References
}

1. Kannel WB. Update on the role of cigarette smoking in coronary artery disease. Am Heart J 1981; 101:319-28.

2. Friedman GD, Petti DB, Bawol RD, Siegelaub AB. Mortality in cigarette smokers and quitters. N Eng J Med 1981; 304:1407-10.

3. Billimorion JD, Pozner H, Metselaar B, Best FW, James DCO. Effect of cigarette smoking on lipids, lipoproteins, blood coagulation, fibrinolysis and cellular components of human blood. Atherosclerosis 1975; 21:61-76.

4. Mustard JF, Murphy EA. Effect of smoking on blood coagulation and platelet survival in man. $\mathrm{Br}$ Med $\mathrm{J} 1963 ; 1: 846-9$.

5. Hawkins RI. Smoking, platelets and thrombosis. Nature $1972 ; 236: 450-2$.

6. Renaud S, Blache D, Dumont D, Theveson $C$, Wissendanger T. Platelet function after smoking in relation to nicotine and carbon monoxide. Clin Pharmacol Ther 1984; 36:289-95.

7. Fuster V, Chesebro JH, Frye RL, Elivebach LR. Platelet survival and the development of coronary artery disease in the young adult: effects of cigarette smoking, strong family history and medical therapy. Circulation 1981; 63:546-51.

8. Ring T, Kristensen SD, Jensen PN, Mourits-Andersen T, Madsen $H$, Dyerberg J. Cigarette smoking shortens the bleeding time. Thromb Res $1983 ; 32: 531-6$.

9. Murchison LE, Fyfe T. Effects of cigarette smoking on serumlipids, blood-glucose and platelet adhesiveness. Lancet 1966; I:182-4.

10. Erikssen J, Hellem A, Stormosken H. Chronic effect of smoking on platelet count and "platelet adhesiveness" in presumably healthy middle-aged men. Thromb Haem 1977; 38:606-11.

11. Wallenburg HCS, van Kessel PH. Platelet lifespan in normal pregnancy as determined by a non-radio-isotopic technique. $\mathrm{Br}$ J Obstet Gynaecol 1978; 85:33-6.

12. McKay DG. Chronic intravascular coagulation in normal pregnancy and pre-eclampsia. Contrib Nephrol 1981; 25:108-11.

13. Letsky EA. Coagulation problems during pregnancy. In: Hytten $F$, Chamberlain $G$, editors. Clinical physiology in obstet-

rics. Chapter 2. The haematological system. Edinburgh: Scientific Publications, 1991:46.

14. Fay RA, Hughes AO, Farron NT. Platelets in pregnancy: hyperdestruction in pregnancy. Obstet Gynecol 1983; 61:23840.

15. Ahmed $\mathrm{Y}$, van Iddehinge B, Paul C, Sullivan MHF, Elder MG. Retrospective analysis of platelet numbers and volumes in normal pregnancy and in pre-eclampsia. $\mathrm{Br} \mathrm{J}$ Obstet Gynaecol 1993; 100:216-20.

16. Hutt R, Ogunniyi SO, Sullivan MH, Elder MG. Increased platelet volume and aggregation precede the onset of preeclampsia. Obstet Gynecol 1994; 83:146-9.

17. Van Wersch JWJ, van Hof AC, Ubachs JMH. The use of an impedance particle counter for the measurement of platelet count, platelet indices and platelet function during pregnancy. Sysmex Int J 1992; 2:44-9.

18. Berglund $U$, Wallenburg $L$, von Schenck $H$. Platelet function and plasma fibrinogen and their relation to gender, smoking habits, obesity and beta-blocker treatment in young survivors of myocardial infaction. Thromb Haemostas 1988; 60:21-4.

19. Dotevall A, Rutti J. Platelet reactivity, fibrinogen and smoking. Eur J Haematol 1987; 38:55-9.

20. Laszlo E, Kaldi N. Kovacs L. Alterations in plasma proteins and platelet functions with ageing and cigarette smoking in healthy men. Thromb Haemostas 1983; 49:150.

21. Belch JJF, McArdle BM, Burns P, Lowe GDO, Forbes CD The effects of acute smoking on platelet behaviour, fibrinolysis and haemorheology in habitual smokers. Thromb Haemostas 1984; 51:6-8.

\author{
Dr. J. W. J. van Wersch \\ Department of Haematology \\ De Wever Hospital \\ P. O. Box 4446 \\ NL-6401 CX Heerlen \\ The Netherlands
}




$$
\text { . }
$$

